\title{
Late Merger in Modal Superlatives: The Case of Levantine Arabic
}

\author{
Abdel-Rahman Abu Helal * \\ Department of English language, AI-Zaytoonah University of Jordan, Jordan
}

Received on: 5-7-2020

Accepted on: 4-1-2021

\begin{abstract}
We present and analyze a pattern of modal superlative constructions in Levantine Arabic (LA) ${ }^{1}$ with an asymmetrical behavior: while the modal construct state superlative construction is ambiguous between the regular modifier and modal superlative readings, the modal attributive superlative is unambiguous and the only reading it has is the regular modifier reading. We propose an explanation for the asymmetry in terms of the (in)applicability of Late Merger of the modal adjective which is, as shown, a necessary compositional stage in deriving the modal superlative reading.
\end{abstract}

Keywords: Attributive Modal Superlatives, Construct State Modal Superlatives, Late Merger, Modal Superlative Reading.

\section{Introduction}

\subsection{Two Superlative Constructions in Levantine Arabic}

Levantine Arabic (LA) has at least two syntactically distinct but semantically equivalent superlative constructions: the genitive superlative construction and the attributive superlative construction as exemplified in (1.a) and (1.b), respectively. ${ }^{2}$

$$
\begin{array}{rrrll}
\text { (1) a. Ali } & \mathrm{t}^{\mathrm{S} l i \varsigma} & \text { Salaa } & \text { dzdzabal } & \text { 1-PSlaa } \\
\text { Ali } & \text { climbed } & \text { on } & \text { the mountain } & \text { the-highest }
\end{array}
$$

'Ali climbed on the highest mountain.'

$\begin{array}{rrrrr}\text { b. Ali } & \text { t'lis } & \text { Salaa } & \text { PYlaa } & \text { dzabal } \\ \text { Ali } & \text { climbed } & \text { on } & \text { highest } & \text { mountain }\end{array}$

'Ali climbed on the highest mountain.'

The two superlative constructions in (1) have the same truth conditions: they are ambiguous between the absolute and relative readings. On the absolute reading, the speaker compares mountains in terms of their height, picks the highest one among a contextually-determined set of mountains, and asserts that Ali climbed that mountain. On the relative reading, on the other hand, the speaker compares Ali to other mountain-climbers in terms of their climbing achievements and asserts that Ali climbed a higher mountain than anyone climbed among the set of contextually relevant climbers (Ross 1964, von Stechow 1984, Szabolcsi 1986, Heim 1985, 1999, Rullmann 1995 and Romero 2011).

๑ 2022 JJMLL Publishers/Yarmouk University. All Rights Reserved,

${ }^{*}$ Doi: https://doi.org/ 10.47012/jjmll.14.1.1

* Corresponding Author: abuhelal8318@gmail.com 


\section{Abu Helal}

The two superlative constructions, however, differ morphosyntactically along two dimensions: first, the pre-modifying PYlaa 'highest' never agrees in morphological definiteness with its associated noun dzabal ' mountain', unlike the post-modifying superlative adjective in (1.a) 'the highest' 1-PSlaa which shows agreement in definite morphology with its associate DP 'the mountain' dzdzabal. Second, while the associate DP in (1.a) is structurally Case marked relative to its positioning in the argument-structure of the sentence, the associate DP in (1.b) is assigned default genitive Case when pre-modified by superlative adjective. As a cover term and for ease of exposition, we will term the superlative construction in (1.a) ' attributive superlative (henceforth A-superlative) and the one in (1.b) as ' genitive superlative (henceforth G-superlative), Ceteris paribus. In what follows, we will lay out the syntax of the two superlative forms. We then outline the semantics of the two structures that deliver the truth conditions of the two readings. We finally present and describe a semantic puzzle associated with the two superlative structures when modified by modal adjectives.

Let us begin with the A-superlative in (1.a). As it stands, the structure represents a proper case of attributive adjectival modification where the superlative adjective morphologically agrees in definite morphology with its associate DP. Such phenomenon is syntactically known as 'determiner spreading ' where the head NP and its adjectival modifiers incorporate the definite article $l$ - 'the' (c.f., Panagiotidis \& Marinis 2011). Following Alexiadou and Wilder (1998), we analyze the determiner spreading construction in (1.b) as reduced relative clauses based on the NP head raising analysis as schematized in (2). Accordingly, the definite article of the adjective is analyzed as relative particle and the respective relative is taken to have a raising syntax based on the head-raising analysis in the spirit of Kayne (1994).

Ouhalla (2004) proposed a syntactic parameter related to the categorial identity of relative clauses: while the relative clause of English-like languages is a CP that of Arabic-like languages is a DP. Both categories of relative clauses have an internal structure of a finite clause, For LA, we assume the reduced relative clause is a DP structure with the relative particle -1 'the' that subcategorizes for $\mathrm{CP}$ (Ouhalla 2004, 290). We schematize the A-superlative in (1.a) as involving a determiners spreading structure with reduced relative clauses of DP category as follows. 


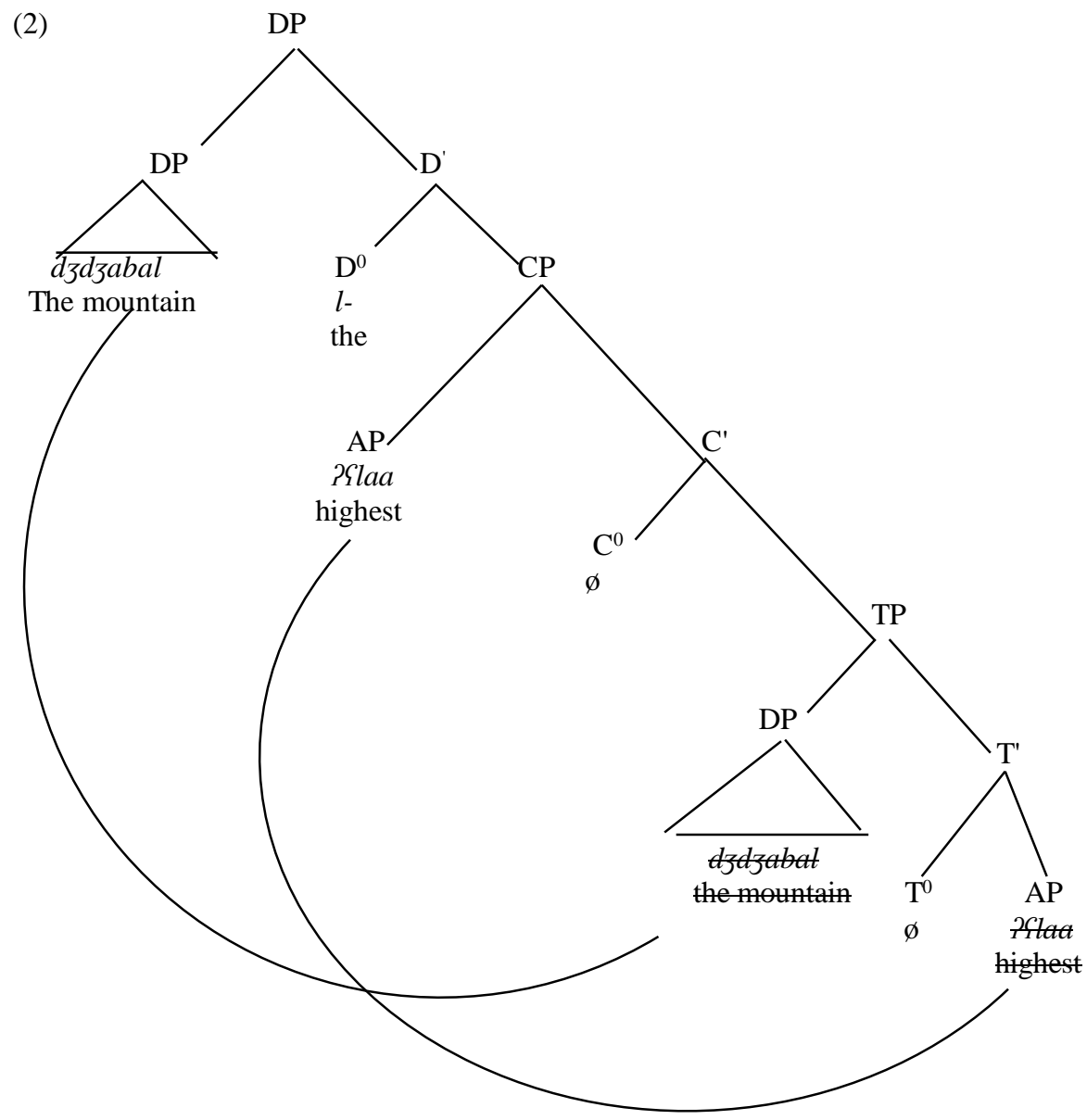

When it comes to the G-superlative construction in (1.b), we show that its superlative structure is a special case of genitive construction that behaves like the construct state structure in (3) in at least three ways (See Elghamry 2003).

(3) kitaab $t^{\mathrm{s}} \mathrm{t}^{\mathrm{f}} \mathrm{aalib}$

book the student-GEN

' the student's book'

First, both kinds of structure may host clitics as shown in (4).
(4) a. kitaab-uhm
book-them
b. PYlaa-uhm
tallest-them
' their book'
'tallest among them'

Second, they are incompatible with definite morphology as in (5).
(5) a. *l- kitaab $t^{\uparrow} t^{\varsigma}$ aalib
the book the student
b. *1-? Ylaa
dzdzabal
' the book of the student'
the-highest the-mountain
' the highest mountain'

Third, they appear to check abstract genitive Case as in $(6)^{3}$.
(6) a. kitaab $t^{\mathrm{f}} t^{\mathrm{f}}$ aalib
b. PYlaa dzabal 
Abu Helal

book the student-GEN

' the student's book' highest mountain-GEN

' highest mountain'

These facts suggest that the G-superlative in (7.a) has the same underlying syntax as other genitive constructions such as construct state constructions. In analyzing the G- superlative in (7.b), we build into two basic syntactic assumptions: first, the DP structure PSlaa dzabal ' highest mountain' parallels the IP/vP structures of nominative and accusative Case domain, respectively: just as the IP constituent involves the head I, the DP PSlā ğabal ' highest mountain' incorporates a functional head (i.e., $\mathrm{D}^{0}$ ) that enters into Agreement and Case assignment relation (i.e., genitive) with an internal NP (Abney 1987, Siloni 1997). Second, the DP structure contains an additional functional category NumbP that is located between DP and NP (Ritter 1991) as schematized in (7) 4

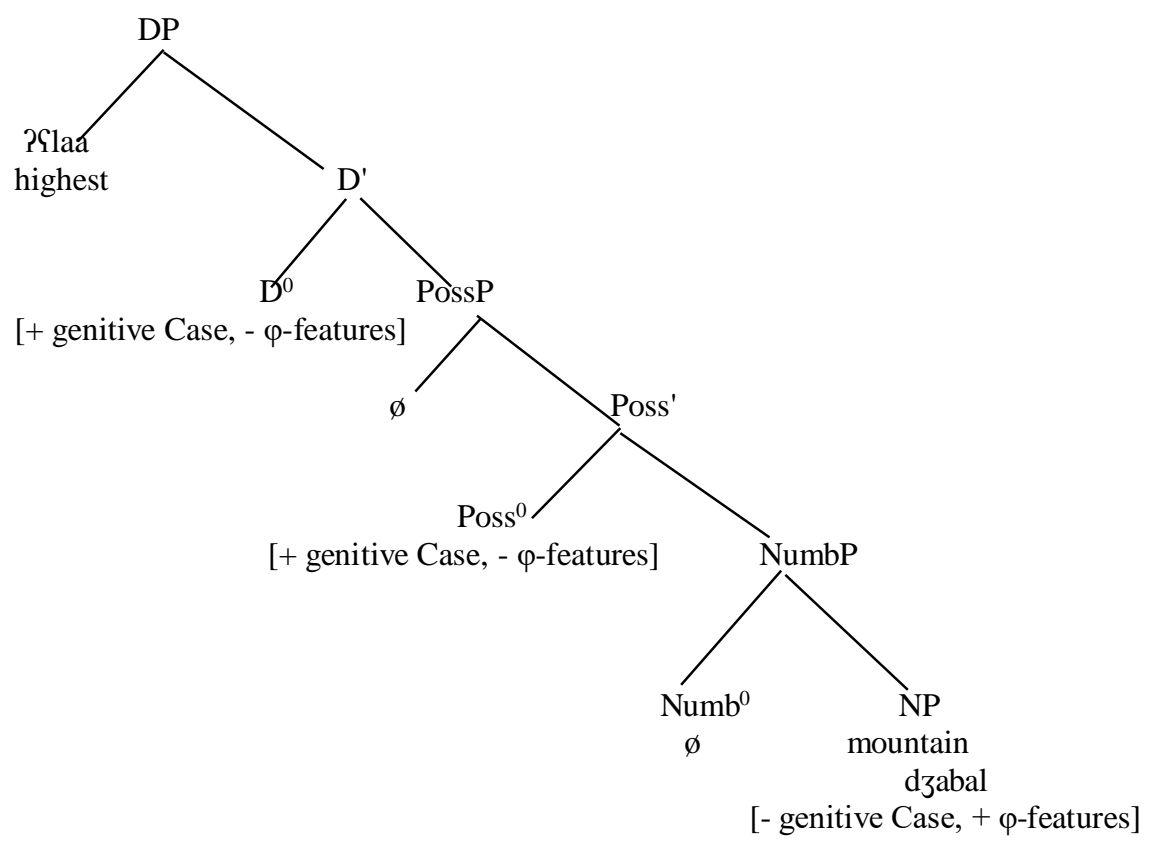

On a minimalist view to Case (Chomsky 1998, 2005), structural Case assignment is achieved structurally by a Goal-Probe Agree operation based on c-command relation. Accordingly, the associate NP dzabal 'mountain' enters enters the derivation with an unvalued genitive Case feature. It then serves as Goal for the c-commanding functional head $\mathrm{D}^{0}$ which serves as Probe that values the genitive Case feature of the associate NP and gets its unvalued $\varphi$-features by virtue of Agree.

In this section, I analyzed the syntax-semantics of two superlative constructions in Levantine Arabic: the A- and G superlative constructions. We showed that both have different syntactic structures as schematized in (2) for the A-superlative and in (7) for the G-superlative. We further show that the two different syntactic structures deliver the same meaning which is ambiguous between the absolute and relative interpretations of the superlative. 
Late Merger in Modal Superlatives: The Case of Levantine Arabic

\subsection{Logical Form of Superlative Construction}

The standard degree-based view has two main working assumptions about gradable adjectives: first, gradable adjectives (e.g., tall) denote relations of individuals and degrees (Seuren 1973; Cresswell 1976; von Stechow 1984; Heim, 1999, 2001) as represented in (8). ${ }^{5}$

$$
\llbracket \text { tall } \rrbracket=: \lambda d . \lambda x \text {. HEIGHT }(x) \geq d
$$

Second, this relation is downward monotonic with the following property:

$$
\left.\forall \mathrm{x} \forall \mathrm{d} \forall \mathrm{d}^{\prime} \text {. [ HEIGHT (d) }(\mathrm{x})=1 \wedge \mathrm{d}^{\prime}<\mathrm{d} \rightarrow \operatorname{HWIGHT}\left(\mathrm{d}^{\prime}\right)(\mathrm{x})=1\right]
$$

As shown in the lexical entry in (1), the gradable adjective is a predicate with two arguments: an individual-denoting object and a degree-denoting one. Syntactically, the degree argument of gradable adjective is represented by a degree phrase that is projected as sister to the gradable adjective. The degree adjective is syntactically represented as the following subtree (10)..

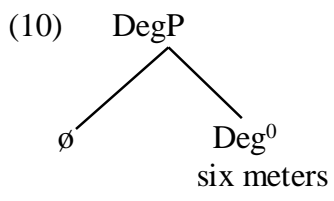

The subtree in (3) can be interpreted as follows.

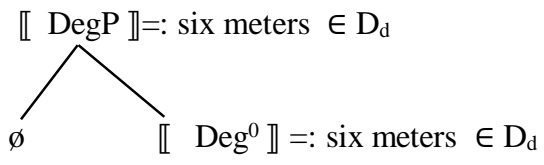

This degree argument composes in two ways: first, it can be directly saturated by degree-denoting measure phrases of type $d$ such as (11) which combines with gradable adjectives via function application as illustrated in (3).

(11) $\llbracket$ DegP tall $\rrbracket=: ~ \llbracket 6$ meter tall $\rrbracket=: ~ \llbracket$ tall $\rrbracket(\llbracket 6$ meter $\rrbracket)$ $\lambda \mathrm{d} . \lambda \mathrm{x} . \operatorname{HEIGHT}(\mathrm{x}) \geq \mathrm{d} \quad(6$ meter $)$ $\lambda x \operatorname{HEIGHT}(x) \geq 6$ meter

Alternatively, the degree argument can be quantified over by a degree operator (e.g., comparative head -er, equative as or the superlative -est). ${ }^{6}$ A possible lexical entry for the superlative operator-est is a two-place predicate (Heim 1999, 2001) as defined in (12). ${ }^{7}$

(12) $\llbracket$-est $\rrbracket=\lambda \mathrm{G} \in \mathrm{D}_{<\mathrm{dt}, \mathrm{t}>} \lambda \mathrm{P} \in \mathrm{D}_{<\mathrm{dt}>.} \exists \mathrm{d}[\mathrm{P}(\mathrm{d}) \wedge \forall \mathrm{Q} \in \mathrm{G}[\mathrm{Q} \neq \mathrm{P} \rightarrow \neg(\mathrm{Q}(\mathrm{D}))]$

The two-place operator in (12) takes as its arguments a comparison class complement $\mathrm{G}$ that denotes a predicate of predicates of degrees of type $<\mathrm{dt}, \mathrm{t}>$ and a predicate of degrees $\mathrm{P}$ of type $<\mathrm{dt}>$. It asserts that there is a degree $\mathrm{d}$ such that it holds true of the property $\mathrm{P}$ and for all other predicates of degrees in the contextually-determined comparison class, if $\mathrm{Q}$ is distinct from $\mathrm{P}$, then it is not the case that the degree $d$ holds true of property Q. For example, the superlative in (1), repeated as (13. ) has a reading in which the speaker compares mountains in terms of their height, picks the highest one among a 


\section{Abu Helal}

contextually-determined set of articles and asserts that Ali climbed that mountain, which is represented as

(14). This is what is called 'absolute reading' (Romero 2011).

$\begin{array}{ccccc}\text { (13) a. Ali } & \text { tilis } & \text { Salaa } & \text { dzdzabal } & \text { 1-PYlaa } \\ \text { Ali climbed } & \text { on } & \text { the mountain } & \text { the-highest }\end{array}$

'Ali climbed on the highest mountain.'

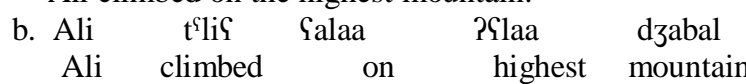

'Ali climbed on the highest mountain.'

(14) Ali climbed the unique y: $\exists \mathrm{d}$ [ y is a d-high mountain $\wedge \forall \mathrm{Q} \in \mathrm{G}[\mathrm{Q} \neq(\lambda \mathrm{d}$ '. $\mathrm{y}$ is a d'-high mountain $) \rightarrow \neg(\mathrm{Q}(\mathrm{d}))]$

The superlative construction in (13) has another reading; the so-called relative reading. On the relative reading, the speaker compares Ali to other mountain-climbers in terms of their climbing achievements and asserts that Ali climbed a higher mountain than anyone climbed among the set of contextually relevant climbers (Ross 1964, von Stechow 1984, Szabolcsi 1986, Heim 1985, 1999, Rullmann 1995 and Romero 2011). It is represented by the following logical form.

(15) $\exists \mathrm{d}[\exists \mathrm{y}$ [Ali climbed y and y is a d-high mountain] $\wedge \forall \mathrm{Q} \in \mathrm{G}[\mathrm{Q} \neq(\lambda \mathrm{d}$ '. Ali climbed a d'high mountain $) \rightarrow \neg(\mathrm{Q}(\mathrm{d}))]$

On a DP-external -est analysis (Szabolcsi 1986; Heim 1999), the absolute/ relative ambiguity is derived through the construction of two logical form structures (LFs). That is, the LF position of the superlative operator [-est $\mathrm{C}$ ] determiners the domain of possible comparison classes of $\mathrm{C}^{8}$

Deriving the absolute reading involves the minimal Quantifier Raising (QRing) of 【 -est G \within the DP l-ğabal l-PSlā 'the highest mountain ' which creates a degree abstract over the degree $\mathrm{d}$ in its base generation position. ${ }^{9}$ Such a movement followed by an N'-internal PRO movement within NP that leaves a trace $\mathrm{t} 2$ of type e. This empty category is to be focus-marked to shape the default absolute reading

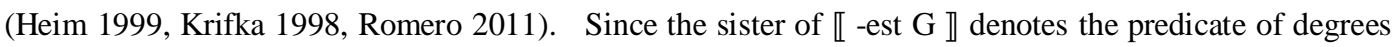
$[\lambda d$. PROx is $d$ - high mountain], each member of $\llbracket \mathrm{G} \rrbracket$ is a predicate of degrees of type $<\mathrm{dt}>$. On this way, the comparison class complement 【-est $\mathrm{G} \rrbracket$ denotes predicates of predicates of degrees of type

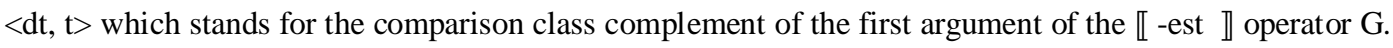
This set of predicates of degrees include the set that PROx and other relevant articles are long to. ${ }^{10}$

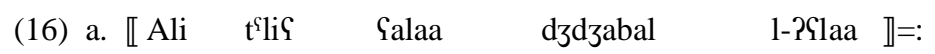

Ali climbed THE 2 [ [--est G] [ 1 [ $\mathrm{t}_{2, \mathrm{~F}} \mathrm{t}_{1}$-high mountain ]] G

b. $\mathrm{G} \subseteq \llbracket 1\left[\mathrm{t}_{2, \mathrm{~F}} \mathrm{t}_{1-}\right.$ high mountain $\rrbracket^{f}$

c. Ali climbed the unique y: $\exists \mathrm{d}$ [ y is a d-high mountain $\wedge \forall \mathrm{Q} \in \mathrm{G}[\mathrm{Q} \neq(\lambda \mathrm{d}$ '. y is a d'-high mountain $) \rightarrow \neg(\mathrm{Q}(\mathrm{d}))]$

The relative reading has a different LF representation. It involves the QRing of the 【-est G \out of the DP into a scope-attaining position (e.g., VP or TP) with the domain of the comparison class G is determined by the new position $\llbracket$-est G $\rrbracket$ resulting into the relative reading as shown in (17).

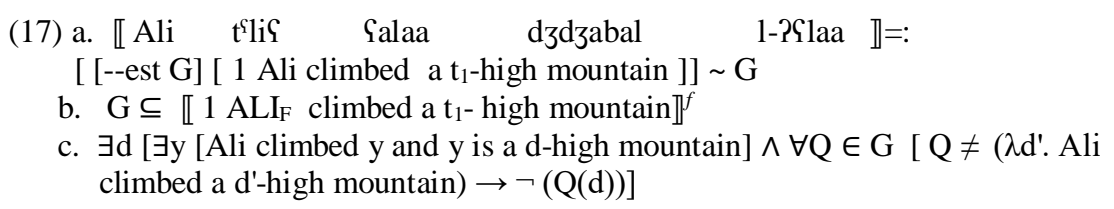


Late Merger in Modal Superlatives: The Case of Levantine Arabic

\subsection{A Semantic Puzzle}

In general, the superlative construction, when modified by modal adjectives, gives rise to an ambiguity between two readings: the so-called regular modifier and modal superlative readings (Corver 1997, Larson 2000, Schwarz 2005, and Romero 2013). As way of example, consider the following modal superlative structure.

(18) Ali climbed the highest possible mountain

The structure in (18) has two readings. On the regular modifier reading, Ali climbed the $\mathrm{x}$ such that $\mathrm{x}$ is possibly a mountain and $\mathrm{x}$ is high to a degree that no other mountain in the relevant contextuallydetermined comparison class is high. On the modal superlative reading, Ali climbed as high a mountain as possible for John or one to climb.

As expected, when a modal adjective modifies a G-superlative in LA, the ambiguity arises as we see in (19).

$\begin{array}{lllll}\text { (19) Ali } \quad \mathrm{t}^{\mathrm{f} l i q} & \text { Salaa } & \text { PSlaa } & \text { dzabal } & \text { momkin } \\ \text { Ali climbed } & \text { on } & \text { highest } & \text { mountain } & \text { possible }\end{array}$

'Ali climbed on the highest mountain possible.'

\section{$\checkmark$ Regular modifier reading:}

Ali climbed the $\mathrm{x}$ such that $\mathrm{x}$ is possibly a mountain and $\mathrm{x}$ is high to a degree that no other mountain in the relevant contextually-determined comparison class is high.

\section{$\checkmark$ Modal superlative reading:}

Ali climbed as high a mountain as possible for John or one to climb.

But quite unexpectedly, the modal superlative reading is blocked in the modified G-superlative and the only reading it has is the regular modifier one.
(20)

\begin{tabular}{|c|c|c|c|c|}
\hline $\begin{array}{l}\mathrm{t}^{\mathrm{f}} \mathrm{liS} \\
\text { climbed }\end{array}$ & $\begin{array}{l}\text { Salaa } \\
\text { on }\end{array}$ & $\begin{array}{l}\text { dzdzabal } \\
\text { the-mountain }\end{array}$ & $\begin{array}{l}\text { 1-PYlaa } \\
\text { the-highest }\end{array}$ & $\begin{array}{l}\text { 1-mhutamal/ } * 1 \text {-momkin } \\
\text { the- probable/the-possible }\end{array}$ \\
\hline
\end{tabular}

'Ali climbed on the highest possible mountain.'

\section{$\checkmark$ Regular modifier reading:}

Ali climbed the $\mathrm{x}$ such that $\mathrm{x}$ is possibly a mountain and $\mathrm{x}$ is high to a degree that no other mountain in the relevant contextually-determined comparison class is high.

\section{* Modal superlative reading:}

Ali climbed as high a mountain as possible for John or one to climb.

As indicated, the two kinds of superlative exhibit an asymmetrical behavior when modified by modal adjectives: while the G-superlative is ambiguous between the regular modifier and modal superlative readings, the A-superlative is unambiguous and the only reading it has the regular modifier reading.

The facts in (19) and (20) present a puzzle: why is the modal superlative reading in GA-superlatives blocked and such a reading is available in G-superlatives?! This paper aims at presenting a unified syntax-semantics analysis that explain the facts in (19) and (20). 


\section{Abu Helal}

The paper is structured as follows. Section 2 reviews the representative literature on adjectively modified relative clauses. It shows that a raising syntax is required for the presence of the low/high ambiguity (Bhatt 2002; Hulsey and Sauerland 2006). Section 3 motivates the working assumption of our proposal. It argues for the claim that the (ya)illi relative clause modified by the superlative is a matching structure with an amount interpretation that serves as the complement comparison class of the QRing superlative operator by later merger. Section 4 presents the desired unified compositional analysis that resolves the puzzle. The last section concludes the paper.

\section{Modal Superlatives}

\subsection{Three Restrictions on Modal Superlative Reading}

It has been observed that the modal superlative reading of (18) is licensed under three main restrictions (Romero 2013, among many others). First, the modal superlative reading involves a restricted set of modal adjectives such as possible in English and momkin ' possible' in LA. Modal adjectives such as probable or mohtamal 'probable' cannot modify superlatives to give rise to the modal superlative reading as exemplified in (21).

(21) Ali climbed the highest probable mountain.

$\checkmark$ Regular Modifier Reading $\quad *$ Modal Superlative Reading

(22) a. Ali tí Salaa PSlaa dzabal mohtamal

Ali climbed on highest mountain probable

'Ali climbed on the highest probable mountain.'

$\checkmark$ Regular Modifier Reading $\quad$ Modal Superlative Reading

b. Ali tilis Salaa dzdzabal 1-PSlaa 1-mћutamal/*1-momkin

Ali climbed on the-mountain the-highest the-probable/ the-possible

'Ali climbed on the highest possible mountain.'

Larson (2000) claimed that only modal adjectives that c-select for non-finite IPs such as possible or momkin support the modal superlative reading. In LA, momkin 'possible' may take a nonfinite IP as its complement, but the modal adjective mohtamal 'probable' may not as shown in (23).

(23) a. momkin la Ali innu yițla؟ Salih possible for Ali that climb. M on-it

' It is possible for Ali to climb it.'

b. *mohtamal la Ali innu yițlaS Salih probable for Ali that climb. M on-it

'It is probable for Ali to climb it.'

The other restriction is that whenever the modal adjective in English is placed post-nominally, only the modal superlative reading arises as shown in (24). Romero (2013) argued that the modal superlative structure in (24) involves an instance of extraposition where the modal adjective undergoes rightward movement. Since light constitutents such as adjectival modifiers cannot extrapose, we have no choice but to take the modal adjective in (24) as heavy constituent comprising of the modal operator along with a reduced elided IP. As Romero (2013) argued, such an assumption is at the heart of the compositional 
Late Merger in Modal Superlatives: The Case of Levantine Arabic

analysis of the LF of modal superlative reading and it rules out the possibility of interpreting postnominal modal adjectives as regular modifiers.

(24) Ali climbed the highest mountain possible.

\section{* Regular Modifier Reading $\quad \checkmark$ Modal Superlative Reading}

The third restriction is the locality condition: for the modal superlative reading to arise, both the superlative operator -est and the modal adjective should be placed in the same local constituency. As shown in the English and LA data (25), whenever an adjective intervenes between the superlative operator and modal adjective, the modal superlative reading is blocked.

(25) I bought the largest affordable possible present.

$\checkmark$ Regular Modifier Reading $\quad *$ Modal Superlative Reading

(Schwarz 2000 as cited in Romero 2013: 84)

The same intervention effect is found in LA as in (26).

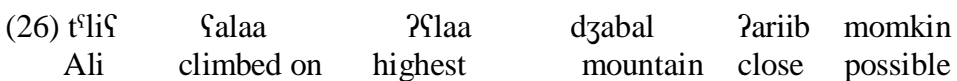

'Ali climbed on the highest close possible mountain.'

' $\boldsymbol{\sim}$ Regular Modifier Reading $\quad *$ Modal Superlative Reading

The LA data we discussed raised a twofold question: first, what blocks the modal superlative reading in LA attributive superlatives with the modal adjective in postnominal position?! Second, what licenses this reading in LA construct state superlatives?! Before addressing these two questions, I find it expedient to review the standtard compositional analysis of Romero (2013) that generates the modal superlative reading in modal superlative constructions.

\subsection{Romero (2013)}

In this section, we review Romero's compositional analysis of modal superlative structures (27).

(27) Ali climbed the highest possible mountain.

Romero's compositional analysis is built into the following steps. First, the modal adjective in modal superlative constructions is interpreted as a heavy constituent where it c-selects for an elided reduced relative clause as shown in (28).

$$
\llbracket \text { possible IP } \rrbracket^{w}=: 1 \text { iff } \exists w^{\prime} . w^{\prime} \in \operatorname{Acc}_{w} \wedge I P\left(w^{\prime}\right)=1
$$

Such a modal adjective is further interpreted as an amount relative clause where its $\lambda$-abstractor ranges over degrees rather than individuals, resulting into an object of type <dt> as exemplified in (29). The denotation of predicate of degrees of type $<\mathrm{dt}>$ is obtained by assuming an instance of degree binding and abstraction.

(29) a. Ali climbed the highest possible mountain.

b. $\lambda \mathrm{d} . \exists \mathrm{w}^{\prime} \in \operatorname{Acc}_{\mathrm{w}} \wedge$ for him /one clime a d- high mountain in $\mathrm{w}^{\prime}$

Second, the denotation of the constituent $\llbracket$ possible IP $\rrbracket^{\mathrm{w}}$ in (28) undergoes type shifting from a predicate of type $\langle\mathrm{dt}\rangle$ into a predicate of predicates of type $\langle\mathrm{dt}, \mathrm{t}\rangle$ by applying the shifter operator to (30): 


\section{Abu Helal}

(30) $\mathrm{SHIFT}_{<\mathrm{dt}>\rightarrow<\mathrm{dt}, \triangleright}=: \lambda \mathrm{D}_{<\mathrm{d}, \mathrm{t}} \lambda \mathrm{D}_{<\mathrm{d}, \mathrm{t}\rangle .} \exists \mathrm{d}^{\prime}\left[\mathrm{D}\left(\mathrm{d}^{\prime}\right) \& \mathrm{D}^{\prime}=\lambda \mathrm{d}^{\prime \prime} . \mathrm{d}^{\prime \prime} \leq \mathrm{d}^{\prime}\left(\left[\lambda \mathrm{d} . \exists \mathrm{w}^{\prime} \in\right.\right.\right.$

$\operatorname{Acc}_{\mathrm{w}} \wedge$ for him /one clime a d- high mountain in w'])

$=: \lambda D^{\prime}<d, \downarrow . \exists d^{\prime}\left[\exists w^{\prime} \in A^{\prime} c_{w} \wedge\right.$ for him /one clime a d'- high

mountain in $\left.\mathrm{w}^{\prime} \& \quad \mathrm{D}^{\prime}=\lambda \mathrm{d}^{\prime \prime} . \mathrm{d}^{\prime \prime} \leq \mathrm{d}^{\prime}\right]$

Third, the predicate of predicates of degrees in (30) directly saturates the first argument of the 2place superlative operator yielding the following Generalized Quantifier DegP:

$$
\operatorname{DegP} \quad \lambda \mathrm{P}_{<\mathrm{d}>} . \exists \mathrm{d}\left[\mathrm { P } ( \mathrm { d } ) \wedge \forall \mathrm { Q } \in \left[\lambda \mathrm{D}^{\prime}<\mathrm{d}, \mathrm{t}>. \exists \mathrm{d}^{\prime}\left[\exists \mathrm{w}^{\prime} \in \operatorname{Acc}_{\mathrm{w}} \wedge\right.\right.\right.
$$

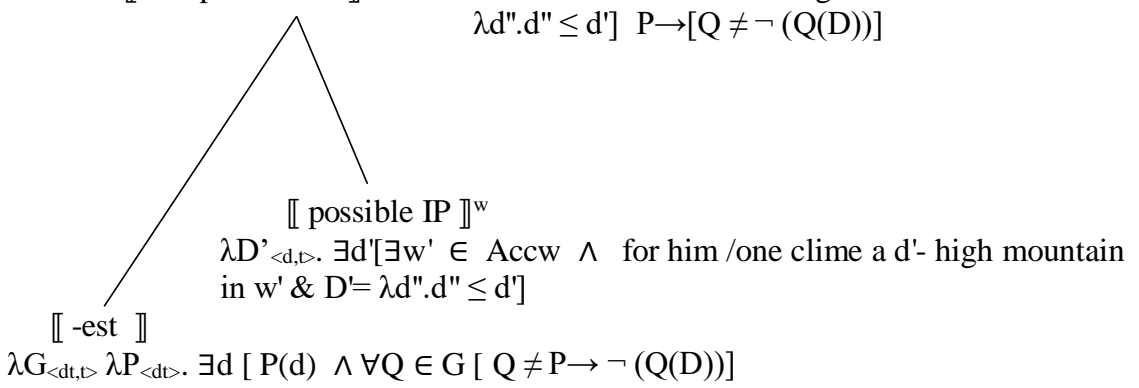

Forth, the generalized quantifier in (31) undergoes QRing at the IP level. Such a movement derives the predicate of degrees in the matrix clause as in (32).

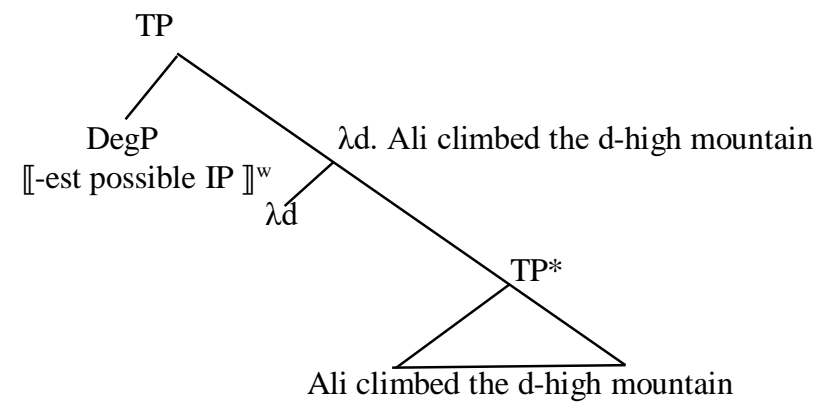

Fifth, the generalized quantifier 【 -est possible IP $\rrbracket^{\mathrm{w}}$ applies to the derived predicate of degrees of the matrix clause to yield the following truth value:

1 iff $\exists$ d [Ali claimbed the d-high mountain $\wedge \forall \mathrm{Q} \in\left[\lambda \mathrm{D}^{\prime}<\mathrm{d}, \mathrm{t}>. \exists \mathrm{d}^{\prime}\left[\exists \mathrm{w}^{\prime} \in \operatorname{Acc}_{\mathrm{w}} \wedge\right.\right.$ for him / one clime a d'- high mountain in $\left.w^{\prime} \& \mathrm{D}^{\prime}=\lambda \mathrm{d}^{\prime} . \mathrm{d}^{\prime \prime} \leq \mathrm{d}\right] \mathrm{P} \rightarrow[\mathrm{Q} \neq \neg(\mathrm{Q}(\mathrm{D}))]$

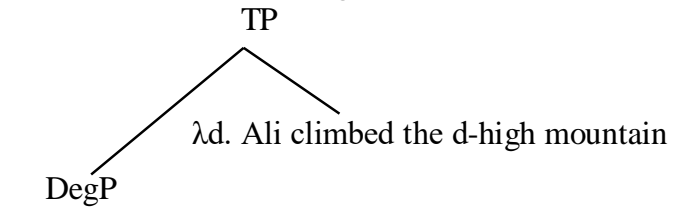

$\llbracket$-est possible IP $\rrbracket^{\mathrm{w}}$

Romero's analysis correctly predicts the three main conditions of the modal superlative reading in modal superlative constructions. First, the analysis only incorporates the set of modal adjectives that subcategorize for IP arguments such as possible in English and momkin ' possible' in LA. Second, the 
Late Merger in Modal Superlatives: The Case of Levantine Arabic

analysis meets the locality condition that brings the superlative operator -est and the modal adjective into a compositionally interpretable local configuration (i.e. DegP). Third, it predicts the postnominal restriction by explaining the default modal superlative reading in terms of extraposition. Since only heavy constituents can extrapose, we have a nice explanation why the regular modifier reading is blocked in the postnominal modal superlative construction.

In what follows, I propose our compositional analysis with a different Schoenfinkelization based on the syntactic assumptions of later merger and phasehooh (Chomsky 2005). I show that such an analysis resolves the puzzle by generating the modal superlative reading in G-superlatives and blocking it in Asuperlatives.

\section{The Proposal}

In this section, I propose a compositional analysis for modal superlative constructions in LA with a special focus on the following pattern: unlike the G-superlative in (34.b) which is ambiguous between the regular modifier and modal superlative readings, the A-superlative in (34.b) is unambiguous and the only reading it has is the regular modifier reading.
(34) a. Ali t'ilis
Salaa
dzdzabal
1-PYlaa 1-muhtamal/*1-momkin
Ali climbed
on
the mountain
the-highest the-probable/ the-possible

'Ali climbed on the highest mountain.'

$\checkmark$ Regular Modifier Reading $\quad \times$ Modal Superlative Reading

$\begin{array}{rrrrrr}\text { b. Ali } & \text { t }^{\text {} l i q} & \text { Salaa } & \text { PSlaa } & \text { dzabal } & \text { momkin } \\ \text { Ali } & \text { climbed } & \text { on } & \text { highest } & \text { mountain } & \text { possible }\end{array}$

'Ali climbed on the highest mountain.'

$\checkmark$ Regular Modifier Reading $\quad \sqrt{ }$ Modal Superlative Reading

I propose a compositional analysis that correctly predicts the pattern in (34). Our analysis is based on the assumption that the modal superlative reading arises when it is possible for the constituent 【 possible

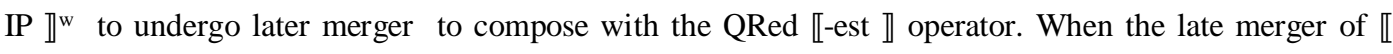
possible IP $\rrbracket^{\mathrm{w}}$ is blocked for whatever reason in grammar, the modal superlative reading doesn't obtain. I show that the reason why the modal superlative reading disappears in (34.a) is that the late merger of the constituent $\llbracket$ possible IP $\rrbracket^{\mathrm{w}}$ is blocked by locality. Before presenting the analysis, we will digress briefly to introduce the notion of late merger which constitutes the main ingredient of our analysis.

\subsection{Assumptions}

\subsubsection{Late Merger}

Chomsky (1995) observed that the following sentence has a reconstruction effect.

(35) *[Which argument that $\mathrm{John}_{\mathrm{i}}$ is a genius] did he $\mathrm{i}_{\mathrm{i}}$ believe [Which argument that $\mathrm{John}_{\mathrm{i}}$ is a genius] ?

(Fox 1999:164 as cited in Takahashi \& Hulsey 2009: 391) 
Abu Helal

To account for the ungrammaticality of (35), Chomsky (1995) proposed the copy theory of movement in which the movement copies in (35) get interpreted in the LF. On this view, the structure in (35) is ruled out as an instance of condition $\mathrm{C}$ violation: interpreting the lower copy [which argument that $\mathrm{John}_{\mathrm{i}}$ is a genius] of the A-bar movement of wh-question results into having the R-expression $\mathrm{John}_{i}$ ccommanded by its referential pronoun $h e$.

It is worth mentioning that A-movement also induces a reconstruction effect as well. The Amovement structure in (36) has a bound-variable reading where the quantificational DP every professor

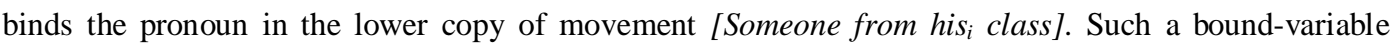
interpretation arises as the consequence of interpreting the lower copy of movement under the ccommand domain of the quantificational binder.

(36) [Someone from his $\mathrm{s}_{\mathrm{i}}$ class] seems to [every professor $]_{\mathrm{i}}$ to be a genius [Someone from

his ${ }_{i}$ class]

Unlike the A-bar movement in (37), the A-movement in (38) bleeds Condition C. This fact presents a puzzle: despite the fact that the two kinds of movement exhibit reconstruction effects, it is far from clear why condition $\mathrm{C}$ is bled in A-movement and at the same time such effect shows in A-bar movement.

(37) *Which argument that $\mathrm{John}_{\mathrm{i}}$ is a genius did he believe ?

(38) a. [The claim that $\mathrm{John}_{\mathrm{i}}$ was asleep] seems to him $\mathrm{i}$ to be correct.

b. [Every argument that $\mathrm{John}_{\mathrm{i}}$ is a genius] seems to him $\mathrm{i}$ to be flawless.

The standard solution to the puzzle is to assume that the expression containing the R-expression in (38) merge late in such a way that the R-expression no longer falls under the c-command domain of its co-referential pronoun. Such an operation is blocked in (37) for independent reasons in grammar (Lebeaux 1988, Fox 2002, Takahashi \& Hulsey 2009, Stanton 2016, among many others). ${ }^{11}$

Similarly, Fox and Nissenbaum (1999) observed that whenever an adjunct is extraposed, it bleeds Condition $\mathrm{C}$ as shown in (39).

a. I gave him $\mathrm{i}$ a picture from $\mathrm{John}_{\mathrm{i}}$ 's collection yesterday

b. I gave him $\mathrm{i}$ a picture yesterday [ from $\mathrm{John}_{\mathrm{i}}{ }^{\text {s collection] }}$.

(Fox \& Nissenbaum 1999: 139)

Fox \& Nissenbaum (1999) offered the analysis in (40) where the DP ' a picture' first QRs across the adverbial 'yesterday' at a higher level and it is then followed by the late merger of adjunct ' from John' collection' which contains the R-expression. As we can see, the late merger of the adjunction removes the R-expression from the c-command domain of its co-referentail pronoun. 
(40)

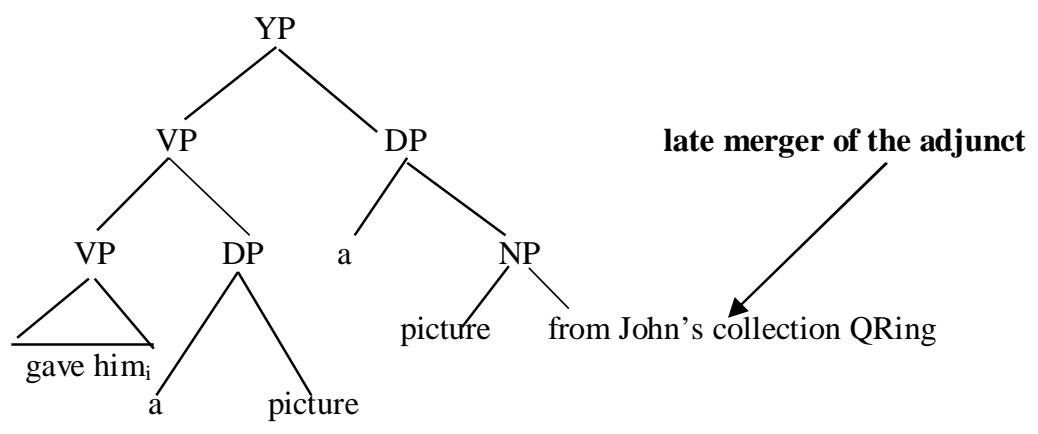

As we can see, the late merger analysis derives condition $\mathrm{C}$ bleeding effect in at least two contexts: A-movement and adjunct extraposition. ${ }^{12}$ Fox (2002) proposed a unified theory that controls the applicability of late merger: it is applicable as long as composition ends up with semantically interpretable output. ${ }^{13}$ Accordingly, the reason why (41.a) is grammatical is that the late merged relative clause 'that $\mathrm{John}_{\mathrm{i}}$ made' may compose with the NP argument to yield a semantically interpretable expression. Since the relative clause 'that $\mathrm{John}_{\mathrm{i}}$ made' denotes a predicate of individuals of type <et> and the NP 'argument' in the moved ' which argument' denotes a predicate of individuals of type <et>, it is possible to combine them via predicate modification yielding a compositionally interpretable object of type <et> as represented in (42) ( Heim and Kratzer 1998).

(41) a. Which argument [that $\mathrm{John}_{i}$ made] did he $i$ believe?

b. Which argument [that $\mathrm{John}_{i}$ is a genius] did he $\mathrm{e}_{i}$ believe?

(Fox 1999, 164)

(42) 【 argument that $\mathrm{John}_{\mathrm{i}}$ was asleep $\rrbracket=: \lambda \mathrm{x} . \mathrm{x}$ is an argument \& John made $\mathrm{x}$.

Fox (2002) proposed a conversion mechanism that interprets the copies of movement chains in the LF. This mechanism converts movement copies into definite descriptions of type e using two derivational steps: first, the variable $[\lambda \mathrm{y}(\mathrm{y}=\mathrm{x})]$ of type $<\mathrm{et}>$ is inserted in such a way that the (Det) Pred turns into (Det) $[$ Pred $\lambda y(y=x)]$ where the Pred and the inserted variable $[\lambda y(y=x]$ compose intersectively as represented in (43).

(43) (Det) $[\lambda y[\operatorname{Pred}(y) \&(y=x)]$

Second, a determiner replacement operation applies in which the Det is replaced by a definite description operator which applies to the predicate of individuals in (43) yielding an object of type e as in (44).

(44) ty $[$ Pred (y) \& (y=x)].

The late merger of the complement 'that $\mathrm{John}_{i}$ is a genius' in (65.b), on the other hand, fails to produce a compositionally interpretable representation and hence late merger should not be an option for cases like (34.b). Applying late merger in (34.b) is blocked on the assumption that lower copy of movement ' which argument' cannot be interpreted via Fox's conversion mechanism. Because the constituent 'which argument' is an object of type $\langle\mathrm{t}$, $\langle\mathrm{et}\rangle\rangle$ which needs to be saturated by a proposition- 


\section{Abu Helal}

denoting argument of type $\mathrm{t}$ as its first argument. QRing this constituent then leaves the lower copy of (Det) $\left[\right.$ Pred $\left.\left.(\mathrm{y}) \in \mathrm{D}_{\langle t\langle e t\rangle}\right]\right]$. It is clear that such a copy cannot be converted into a definite description: the inserted variable $\lambda y(y=x)]$ of type <et> cannot compose with the predicate Pred $(y)$ of type $\langle t<e t>>$ and hence an instance of unresolvable type mismatch ensues. Therefore, the argument [that $\mathrm{John}_{\mathrm{i}}$ is a genius] which is of type t needs to compose directly in the base generated position and then QRing takes place. In this way, there is no way possible to apply Late Merger with compositionally interpretable output.

\subsubsection{The Phase Theory}

Under minimalism, syntactic computation is performed phase by phase in a bottom-up manner. Chomsky (2001) proposed the phase impenetrability condition that governs syntactic derivation cyclically in such a way that Spell out involves minimal constituents of semantic and phonological realizations (i.e., $\mathrm{CP}$ or light vP), rather than whole sentences. Accordingly, two conditions follow as far as minimal computation is concerned. First, the phase complement (i.e., TP or VP) is shipped to the interfaces via Spell-out leaving its edge (i.e., head and specifier) transparent to further syntactic operations and processes (Chomsky 2005) ${ }^{14}$. Second, whenever a constituent $\alpha$ is to undergo later merger with a constituent $\beta$, a phase condition of late merger applies (Abe 2018: 95): late merger should take place no later than completion of the phase that contain both $\alpha$ and $\beta$. Abe (2018: 94) motivated this condition in his analyzing the following pattern:

(45) a. *Zelda sent him 1 back all Dr. Levin,'s flowers.

b. Zelda sent him 1 back all the flowers which Dr. Levin ${ }_{1}$ had bought for her.

(Abe 2018, 94)

Abe (2018) nicely explains the acceptability of (45.b) in terms of late merger. He suggested that the late merger of the relative clause ' which Dr. Levin 1 had bought for her' does not take place until the completion of the $\mathrm{vP}$ and $\mathrm{CP}$ phases that dominate the relative clause that contain the R-expression and its modifiee containing the R-expression's co-referential pronoun, respectively. Since both objects belong to different phases, the dominating co-referential pronoun cannot c-command its R-expression, resulting into condition C obviating effect, unlike (45.a).

\subsection{Deriving the modal superlative reading in $G$-superlatives}

Recall that the construct state superlative in (46) allows for the modal superlative reading in which Ali climbed as high a mountain as possible for him/ one to climb.

$$
\begin{array}{cccccc}
\text { Ali } & \text { t'lis } & \text { Salaa } & \text { PSlaa } & \text { dzabal } & \text { momkin } \\
\text { Ali } & \text { climbed } & \text { on } & \text { highest } & \text { mountain } & \text { possible }
\end{array}
$$

'Ali climbed on the highest mountain.'

To derive the modal superlative reading of (46), we assume the late merger of the constituent 【 possible IP $\rrbracket^{\mathrm{w}}$ to combine with the -est degree operator as its complement comparison set. On this

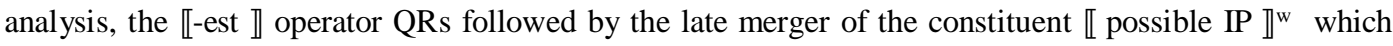
saturates the operator's first argument. 
Late Merger in Modal Superlatives: The Case of Levantine Arabic

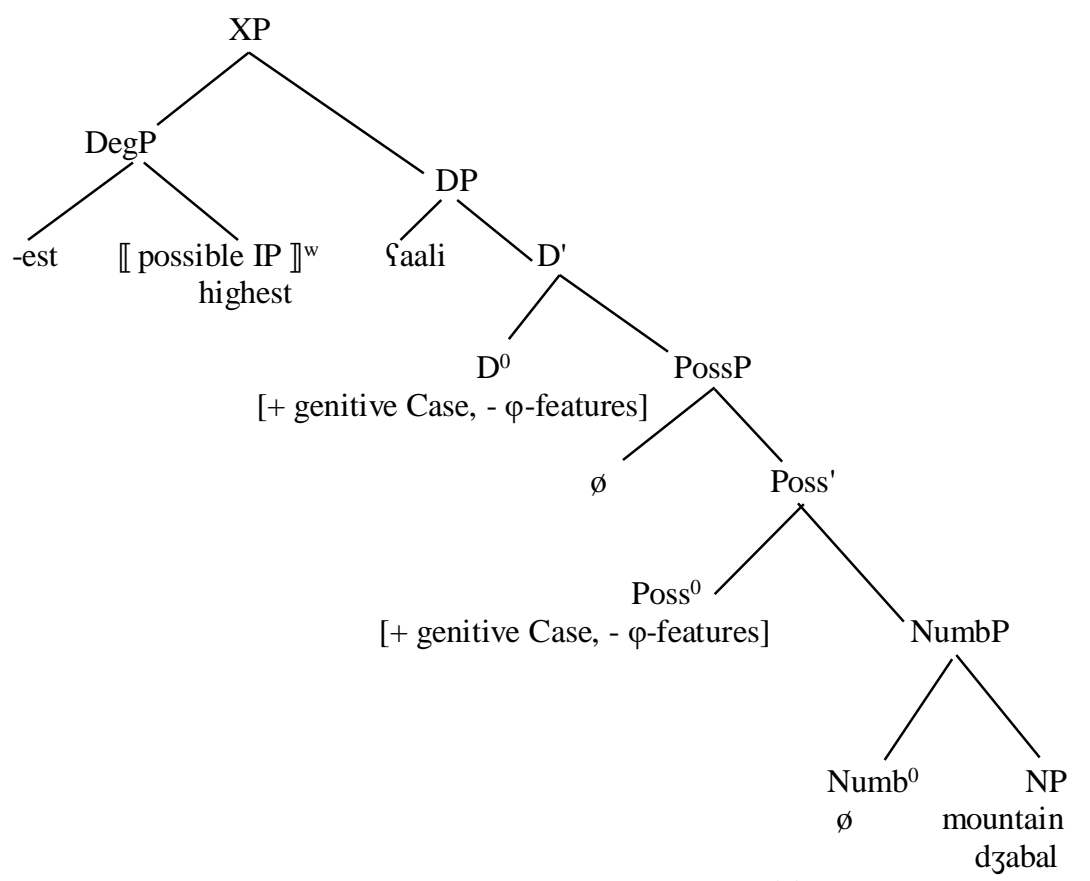

[- genitive Case, $+\varphi$-features]

Using the syntactic structure in (47), we can calculate the truth conditions of the modal superlative reading as follows.

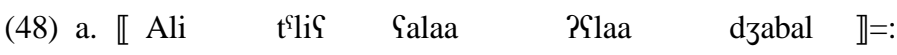

b. LF: Ali climbed THE 2 [ [--est $\llbracket$ possible IP $\left.\rrbracket^{\mathrm{w}}\right]$ [ 1 [ $\mathrm{t}_{2, F}$ t1-high mountain ]]

c. Ali climbed THE $2\left[\left[\lambda \mathrm{P}_{\langle\mathrm{d} \downarrow} . \exists \mathrm{d}\left[\mathrm{P}(\mathrm{d}) \wedge \forall \mathrm{Q} \in\left[\lambda \mathrm{D}^{\prime}<\mathrm{d}, \mathrm{t}\right\rangle . \exists \mathrm{d}^{\prime}\left[\exists \mathrm{w}^{\prime} \in\right.\right.\right.\right.$ Accw $\wedge$

for him / one clime a d'- high mountain in w'\& $\left.\mathrm{D}^{\prime}=\lambda \mathrm{d}^{\prime \prime} . \mathrm{d}^{\prime \prime} \leq \mathrm{d}^{\prime}\right] \rightarrow[\mathrm{Q} \neq \neg(\mathrm{Q}(\mathrm{d}))]$

d. Ali climbed the unique y: $\exists d\left[y\right.$ is a d-high mountain $\wedge \forall Q \in\left[\lambda \mathrm{D}^{\prime}<\mathrm{d}, \mathrm{b} . \exists \mathrm{d}^{\prime}\left[\exists \mathrm{w}^{\prime}\right.\right.$

$\in \operatorname{Acc}_{w} \wedge$ for him / one clime a d'- high mountain in w'\& $\left.\mathrm{D}^{\prime}=\lambda \mathrm{d}^{\prime \prime} . \mathrm{d}^{\prime \prime} \leq \mathrm{d}^{\prime}\right][\mathrm{Q} \neq$

$\left(\lambda d^{\prime}\right.$. y is a $\quad d^{\prime}$-high mountain $\left.) \rightarrow \neg(Q(d))\right]$

\subsection{Blocking the Modal Superlative reading in A-superlative}

In the following superlative construction, the modal superlative reading is blocked.
(49) Ali t'liৎ Salaa dzzzabal
1-PYlaa
1-mћutamal/ ???1-momkin
Ali climbed on
the-mountain the-higest
possible

'Ali climbed on the highest possible mountain.'

\section{$\checkmark$ Regular Modifier Reading $\quad \times$ Modal Superlative Reading}

We account for the fact in (49) by assuming that the locality condition necessary for the modal to be superlative reading is not met. Following Alexiadou \& Wilder's (1998), the modal superlative in (49) is a case of determiner doubling construction with the following recursive reduced relative clause analysis. 
Abu Helal

(49)

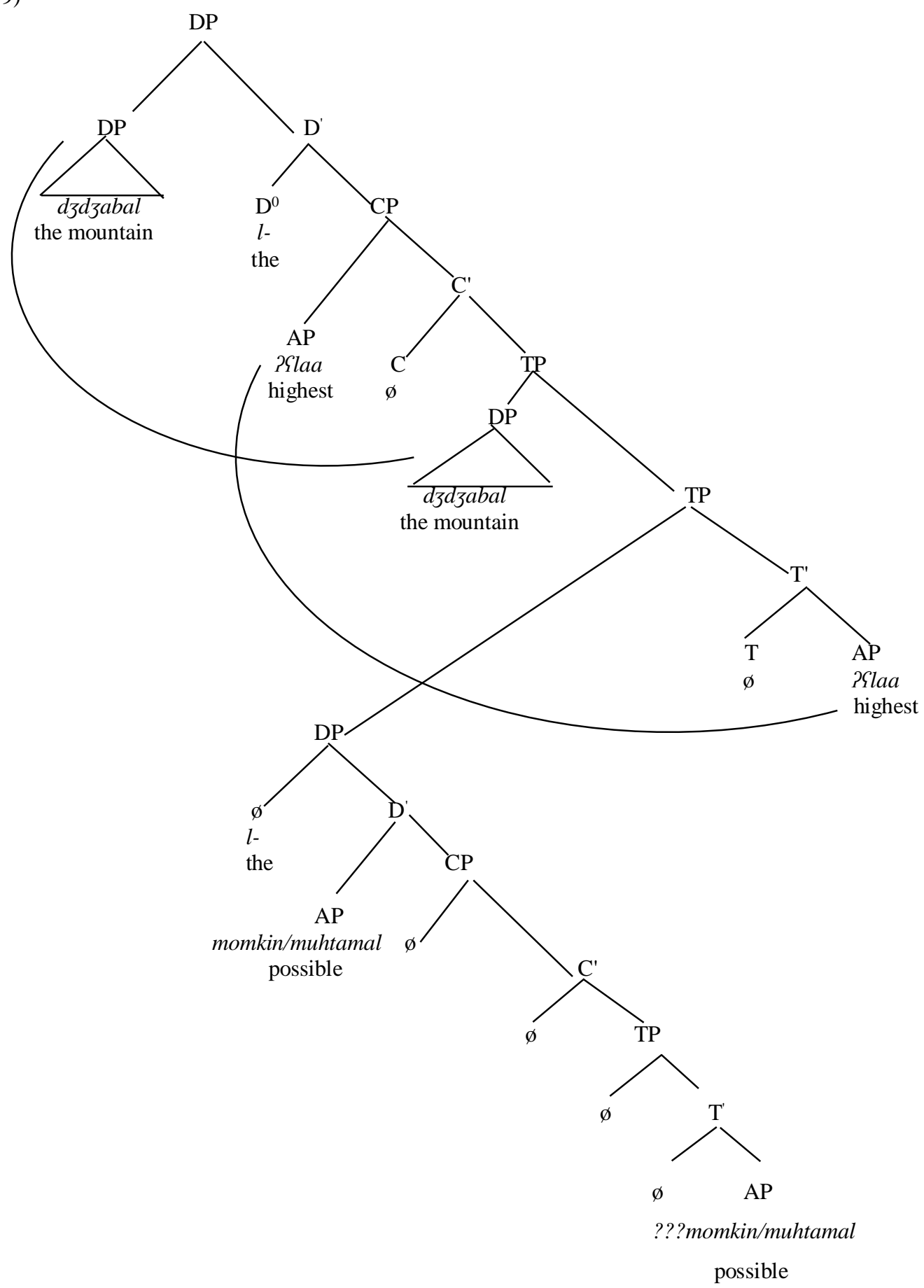

We show that the syntax in (49) lacks a modal superlative reading due to the fact that the locality requirement of this reading cannot be satisfied.

First, to derive the truth conditions of the modal superlative reading, the heavy constituent 【 possible IP $\rrbracket^{\mathrm{w}}$ needs to undergo late merger to saturate the first argument of the QRed superlative operator. Late 
merger of the constituent $\llbracket$ possible IP $\rrbracket^{\mathrm{w}}$ takes place under two conditions: first, it should yield a compositionally interpretable object in satisfaction of the LF interpretability condition (Fox 2002). Therefore, $\llbracket$ possible IP $\rrbracket^{\mathrm{w}}$ should be interpreted as a predicate of predicates of degrees to be able to saturate the first argument of the QRed superlative operator.

Second, the late merger of $\llbracket$ possible IP $\rrbracket^{\mathrm{w}}$ should take place no later than completion of the phase that contain $\llbracket$ possible IP $\rrbracket^{\mathrm{w}}$ and its modifiee ( Abe 2018: 95).

When interpreting the tree (49), the first condition can in principle be met: on the assumption that $\llbracket$ possible IP $\rrbracket^{\mathrm{w}}$ denotes a predicate of predicates of degrees of type $\langle\mathrm{dt}, \mathrm{t}\rangle$, the QRed $\llbracket$-est $\rrbracket$ modifier, had there been applied, combines with the denotation of the modifiee $\llbracket$ possible IP $\rrbracket^{w}$ yielding a compositionally interpretable object.

The second condition, on the other hand, cannot be satisfied. The modifier $\llbracket$ possible IP $\rrbracket^{\mathrm{w}}$ and its modifiee the QRed -est belong to different phases: the modifier 【 possible IP $\rrbracket^{\mathrm{w}}$ belongs to the phase

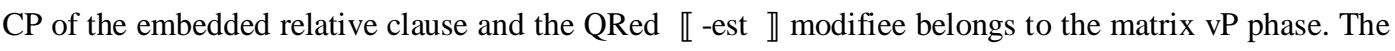
late merger of $\llbracket$ possible IP $\rrbracket^{\mathrm{w}}$ to combine with the superlative - est is blocked and hence the modal superlative reading doesn't arise.

(50) a. Phase $1 \mathrm{vP}$ ( QRing of -est)

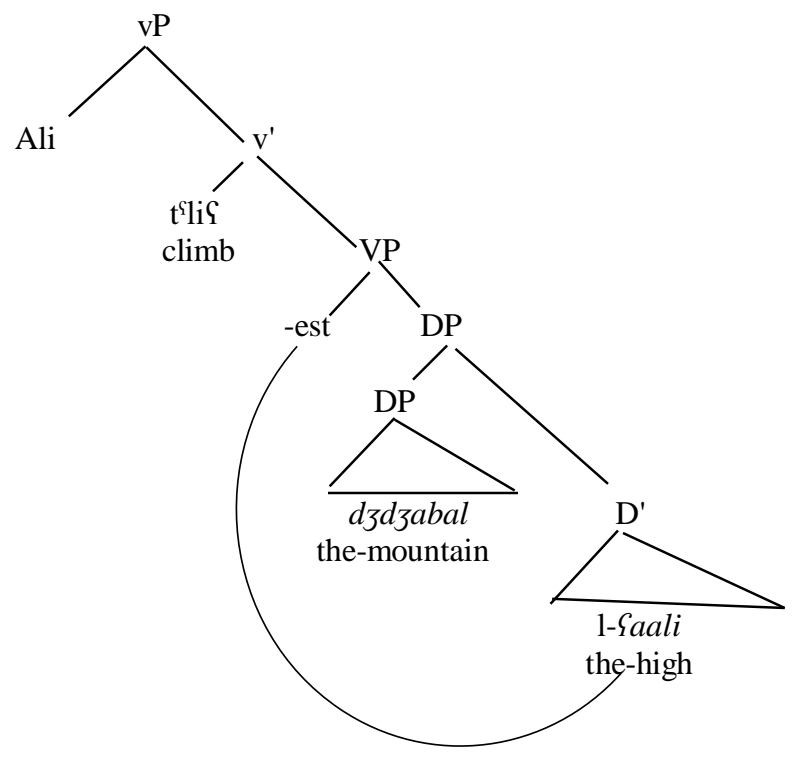


b. Phase $2 \mathrm{CP} \quad\left(\llbracket\right.$ possible IP $\left.\rrbracket^{\mathrm{w}}\right)$

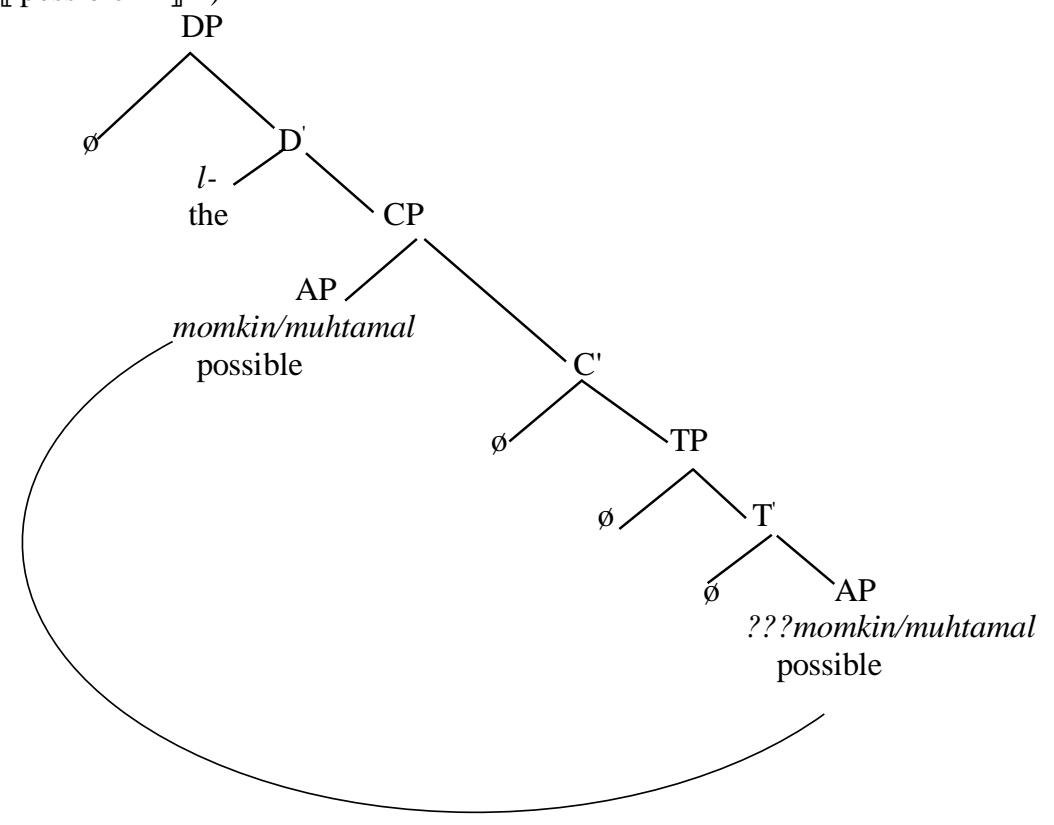

Since the modifier $\llbracket$ momkin IP $\rrbracket^{\mathrm{w}}$ is the complement of the CP phase of the relative clause $(50 . b)$, it is subject to a mechanism of transfer where the complement $\llbracket$ momkin IP $\rrbracket^{\mathrm{w}}$ is transferred to both the

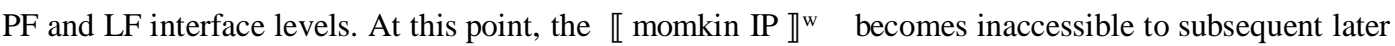

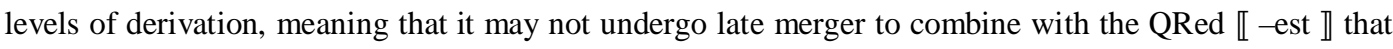
is located in the vP phase of the matrix clause.

Because there is no way to apply the later merger of $\llbracket$ momkin IP $\rrbracket^{\mathrm{w}}$ under the syntax of the double determiner construction in (2), the modal superlative reading is necessarily blocked.

Notice that our analysis nicely predicts the following pattern.
a. Ali tilis
Salaa dzdzabal
1-PSlaa
1-mhutamal
Ali climbed on the-mountain the-higest
the-propoable

'Ali climbed on the highest possible mountain.'
b. *Ali $\mathrm{t}^{\mathrm{f}} \mathrm{liq}$
Salaa dzdzabal
1-PSlaa
1-momkin
Ali climbed on
the-mountain the-higest
the-possible

'Ali climbed on the highest possible mountain.'

Since the adjective momkin ' possible' is a heavy constituent that is realized as anount predicate which subcategorizes for non-finite IPs as evidenced by the fact in (23), repeated as (52),

$$
\begin{aligned}
& \text { momkin la Ali innu yițlas Salih } \\
& \text { possible for Ali that climb. M on-it }
\end{aligned}
$$

' It is possible for Ali to climb it

$\llbracket$ momkin IP $\rrbracket^{\mathrm{w}}$ enters the derivation in (51.b) as an expression of type <dt,t> (i.e., after being typeshifted as represented in (52)).

(52) $\lambda \mathrm{D}^{\prime}<\mathrm{d}, \triangleright ., \exists \mathrm{d}^{\prime}\left[\exists \mathrm{w}^{\prime} \in \mathrm{Acc}_{\mathrm{w}} \wedge\right.$ for him /one clime a d'- high mountain in $\mathrm{w}^{\prime} \& \mathrm{D}^{\prime}=\lambda \mathrm{d}^{\prime \prime} . \mathrm{d}^{\prime \prime} \leq$ 
Late Merger in Modal Superlatives: The Case of Levantine Arabic

d']

This is the wrong type to compose with the denotation of 【 Slaa-d \which is a predicate of individuals in (49).

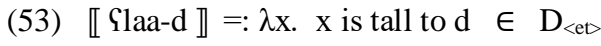

The adjective mohtamal ' probable', being a light constituent, cam be interpreted as predicate of individuals.

(54) *mohtamal la Ali innu yițlaS Salih
probable for Ali that climb. M on-it
'It is probable for Ali to climb it.'

With this denotation of type <et>, it can compose with the denotation of the adjective in (53) by predicate modification (Heim \& Kratzer 1998).

\section{Conclusion}

In this paper, we showed that modal construct state and modal attributive superlatives in LA have an asymmetrical behavior: while the modal construct state superlative is ambiguous between the modal superlative and regular modifier readings, the modal attributive superlative is unambiguous and the only reading it has is the regular modifier one.

We explained the asymmetry by postulating that the modal superlative reading is generated by the late merger of the modal adjective to saturate the first argument of the QRed superlative operator. We specified two conditions that control the applicability of late merger: first, late merger should give rise to a compositionally interpretable output (Fox 2002). Second, later merger should take place no later than completion of the phase that contains the constituent and its modifiee (Abe 2018).

We further showed and demonstrated that the late merger of the adjunct 【 possible IP $\rrbracket^{\mathrm{w}}$ is applicable in G-superlatives: it yields a compositionally interpretable object by getting the constituent 【 possible IP $\rrbracket^{\mathrm{w}}$ of type $\langle\mathrm{dt}, \mathrm{t}\rangle$ saturating the first argument of the QRed operator of type $\langle\mathrm{dt}, \mathrm{t}\langle\mathrm{dt}\rangle\rangle$. It is not dominated by a phase so that it can merge alone without awaiting the completion of a dominating phase.

When it comes to modal attributive superlative, late merger is blocked due to violating the second condition on late merger: the constituent $\llbracket$ possible IP $\rrbracket^{\mathrm{w}}$ cannot undergo late merger until the completion of the phase immediately dominating the constituent. Since the constituent $\llbracket$ possible IP $\rrbracket^{\mathrm{w}}$ is embedded by the relative clause of type $\mathrm{CP}$, the composition produces an object of type $\langle\mathrm{e}\langle\mathrm{dt}\rangle\rangle$ which is the wrong type to compose with the QRed superlative operator. As a consequence, an instance of unresolved type of mismatch arises and the late merger cannot be fulfilled. Given the inapplicability of late merger, the modal superlative reading disappears. 
Abu Helal

\section{الاندماج المتاخر للتفضيل: العربية المشرقية مثالاً \\ عبد الرحمن أبو هلال \\ قسم اللفة الإنجليزية، جامعة الزيتونة الأردنية، الأردن

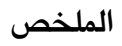

في هذا البحث نقدم نمطاً من صيغ التفضيل في اللفة العربية المحكية في المشرق المتوسط الذي يظهر المشكلة

المعنوية التالية: بينما تعبر صيغة الإضافة التفضيلية لبساً في المعنى بين التفسير الملحق والتفسير المعرفي للتفضيل - تمتلك

الصيغة التفضيلية التابعية قراءة واحدة، وهي قراءة التفسير الملحق للتفضيل فقط. قدمنا حلاً للمشكلة يقوم على آلية

الاندماج المتأخر في النحو التي هي متطلب ضروري لاشتقاق القراءة المعرفية، إذ إن الاندماج المتأخر ينسحب على تفضيل

الإضافة وليس على تفضيل التتابع.

الكلمات المفتاحية: تفضيل الإضافة، تفضيل التتابع، الاندماج النحوي المتأخر، القراءة الملحقية والمعرفيَة. 
Late Merger in Modal Superlatives: The Case of Levantine Arabic

\section{Endotes}

1 The phenomenon under consideration is used in all varieties of Levantine Arabic , mainly Jordanian, Syrian, Palestinian, Lebanese and Çukurovan Arabic in Southern Turkey.

${ }^{2}$ Another way of forming the superlative is to have the morpheme aktar 'most' appended to the NP comprising of $\mathrm{N}$ followed by a postnominal adjective as exemplified in (1). We are not analyzing this type of superlatives. For more information on this type of superlative constructions, see Hallman (2016).

1. Ali țlą Gala aktar ğabal Pali

Ali climbed on more mountain high

'Ali climbed on the highest mountain.

${ }^{3}$ As suggested by an anonymous reviewer, one way to detect genitive case in G-superlatives is to show that the genitive case assigner is inseparable from its nominal case assignee. This is indeed the case since the internal genitive Case assigning $\mathrm{D}^{0}$ is inseparable from its Case nominal assignee in both construct state and A-superlative constructions in (7.a) and (7.b), respectively.

${ }^{4}$ Such projection received support from the fact that genitive constructions may include additional functional layers associated with quantificational or number phrases such as $i$.

1. PYlaa talat dzbaal / PSlaa kull dzabal highest three mountains/ highest every mountain ' highest of three mountains/ highest of every mountain'

5 To represent the linguistic expressions of this paper in meta-language terms, I use a lambda calculus with the following types and relations as listed in (i)):

\section{Types:}

a. e for individual $\in D_{\mathrm{e}}$

b. $\mathrm{t}$ for truth values $\in \mathrm{D}_{\mathrm{t}},\{0,1\}$

c. $\mathrm{d}$ for degrees $\in \mathrm{D}_{\mathrm{d}}$

d. If $\alpha$ and $\beta$ are types, $<\alpha, \beta>$ is a type $\in D<\alpha, \beta>$ (a function that takes elements of type $\alpha$ as its input and produces elements of type $\beta$ as its output).

\section{Extensional relations:}

a. Lexicon: if $\alpha$ is a lexical entry of type a, then $\llbracket \alpha \rrbracket^{\mathrm{i}, \mathrm{g}}=\mathrm{F}(\alpha)$

b. Assignment Function: If $x$ is a variable of type $a$, then $\llbracket x \rrbracket^{i, g}=g(x), g(x) \in D_{a}$

c. Function Application :If $\alpha$ is a functor of type $<a b>$ and $\beta$ is of type $<a>$, then

$$
\llbracket \alpha \beta \rrbracket^{\mathrm{i}, \mathrm{g}}=: \llbracket \alpha \rrbracket^{\mathrm{i}, \mathrm{g}}\left(\llbracket \beta \rrbracket^{\mathrm{i}, \mathrm{g}}\right)
$$

d. Predicate Modification: If $\alpha$ and $\beta$ are of type $<$ at $>$, then $\llbracket \alpha \beta \rrbracket^{\mathrm{i}, \mathrm{g}}=\lambda \mathrm{x} \in \mathrm{D}_{\mathrm{a}} \cdot \llbracket \alpha \rrbracket^{\mathrm{i}, \mathrm{g}}(\mathrm{x}) \&$

$$
\llbracket \beta \rrbracket^{\mathrm{i}, \mathrm{g}}(\mathrm{x})
$$

e. $\lambda$. abstraction: If $\mathrm{x}$ is a variable of type a and $\alpha$ is an object of type $\mathrm{b}$, then

$$
\llbracket \lambda \mathrm{x} . \alpha \rrbracket^{\mathrm{i}, \mathrm{g}}(\mathrm{x})=\lambda \mathrm{u} \in \mathrm{D}_{\mathrm{a}} \cdot \llbracket \alpha \rrbracket[\mathrm{x} / \mathrm{u}]
$$

f. $\llbracket \alpha \mathrm{a}=\beta \mathrm{a} \rrbracket^{\mathrm{i} g}=1$ iff $\llbracket \alpha \mathrm{a} \rrbracket^{\mathrm{i}, \mathrm{g}}=\llbracket \beta \mathrm{a} \rrbracket^{\mathrm{i}, \mathrm{g}}$ 
g. $\llbracket \neg \alpha \rrbracket^{\mathrm{i}, \mathrm{g}}=1$ iff $\llbracket \alpha \rrbracket^{\mathrm{i}, \mathrm{g}}=0$

h. $\llbracket \alpha \mathrm{t} \wedge \beta \mathrm{t} \rrbracket^{\mathrm{i}, \mathrm{g}}=1$ iff $\llbracket \alpha \rrbracket^{\mathrm{i}, \mathrm{g}}=\llbracket \beta \rrbracket^{\mathrm{i}, \mathrm{g}}=1$

i. $\llbracket \alpha \mathrm{t} \vee \beta \mathrm{t} \rrbracket^{\mathrm{i}, \mathrm{g}}=1$ iff $\llbracket \alpha \rrbracket^{\mathrm{i}, \mathrm{g}}=1$ or $\llbracket \beta \rrbracket^{\mathrm{i}, \mathrm{g}}=1$

j. $\llbracket \alpha \mathrm{t} \rightarrow \beta \mathrm{t} \rrbracket^{\mathrm{i}, \mathrm{g}}=1$ iff $\llbracket \alpha \rrbracket^{\mathrm{i}, \mathrm{g}}=0$ or $\llbracket \beta \rrbracket^{\mathrm{i}, \mathrm{g}}=1$

$\mathrm{k}$. $\lambda \lambda \mathrm{xa} \beta \mathrm{t} \rrbracket^{\mathrm{i}, \mathrm{g}}=:$ the function $\mathrm{r}: \mathrm{D}_{\mathrm{a}} \rightarrow \mathrm{D}_{\mathrm{tv}}$ such that $\mathrm{r}(\mathrm{y})=\llbracket \beta \mathrm{t} \rrbracket^{\mathrm{i}, \mathrm{g}^{\prime}}$ where $\mathrm{g}^{\prime}[\mathrm{x}] \mathrm{g}$ and $\mathrm{g}^{\prime}(\mathrm{x})=\mathrm{y}$

1. $\llbracket \exists x a \beta t \rrbracket^{i, g}=1$ iff there is a $g^{\prime}[x] g$ and $\llbracket \beta \rrbracket^{i, g^{\prime}}=1$

m. $\llbracket \forall x a \quad \beta t \rrbracket^{i, g}=1$ iff for all g’$[x] g:[[\beta]] i, g^{\prime}=1$.

${ }^{6}$ We may take measure phrases as generalized quantifiers that denote predicates of degrees of type $\langle\mathrm{dt}, \mathrm{t}\rangle$. Then, they can undergo Quantifier Raising and degree abstraction in such a way that the degree argument is quantified over just as other degree modifiers that function as degree quantifiers (Schwartzschild and Wilkinson 2002).

7 Another lexical item of the superlative operator exists as defined in the lexical entry (i). It is represented as a 3-place predicate that applies to three arguments individual-denoting objects, a predicate of individuals and a gradable adjective. The application of this operator yields the truth conditions in which there is a degree $\mathrm{d}$ such that the individual $\mathrm{x}$ has a property $\mathrm{P}$ to that degree and all the other individuals in the contextually determined comparison class $\mathrm{G}$ don't have the property to $\mathrm{d}$ (See Romero 2011 for an assessment of the superlative as a 2-place and 3-place predicate).

1. $\llbracket$-est $\rrbracket=\lambda \mathrm{G} \in \mathrm{D}_{<\mathrm{e}, \mathrm{t}} \lambda \mathrm{P} \in \mathrm{D}_{<\mathrm{dt}, \mathrm{t}>} \lambda \mathrm{x} \in \mathrm{D}_{<\mathrm{e}>} . \exists \mathrm{d}[\mathrm{P}(\mathrm{d})(\mathrm{x}) \wedge \forall \mathrm{y} \in \mathrm{G}[\mathrm{y} \neq \mathrm{x} \rightarrow \neg(\mathrm{P}(\mathrm{d})(\mathrm{y}))]$

${ }^{8}$ On the DP-internal -est analysis (Heim 1985, Sharvit \& Stateva 2002), the ambiguity is contextuallydetermined: the superlative operator involves a contextual variable $\mathrm{C}$ that is valued by context in such a way that it denotes a set of contextually-determined mountain in the absolute reading and a set of mountains climbed by contextually-determined individuals. The superlative operator undergoes minimal QR within the DP along with its restrictor $\mathrm{C}$ that is valued by context to derive the ambiguity.

1. a. Absolute Reading: Ali climbed the unique $\mathrm{x}$ such that $\exists \mathrm{d}$ [ $\mathrm{x}$ is a ,mountain and $\mathrm{x}$ is d-high $\wedge \forall \mathrm{Q}$ $\in \mathrm{C}\left[\mathrm{Q} \neq\left(\lambda \mathrm{d}^{\prime} . \mathrm{x}\right.\right.$ is a d'- high mountain $\left.\left.) \rightarrow \neg \mathrm{Q}(\mathrm{d})\right]\right]$

b. Relative Reading: $\exists \mathrm{d}[\exists \mathrm{x}[\mathrm{x}$ is a mountain and $\mathrm{x}$ is d-high and Ali climbed $\mathrm{x}] \wedge \forall \mathrm{Q} \in \mathrm{C}[\mathrm{Q} \neq$ $(\lambda d$ '. Ali climbed a d'-high mountain $) \rightarrow \neg \mathrm{Q}(\mathrm{d})]$

${ }^{9}$ It is worth mentioning that focus may reshape the contextually-determined comparison class $\mathrm{G}$. The reshaping of comparison class is achieved by the squiggle operator $\sim$ in such a way that $\mathrm{G}$ must be a subset of the focus semantic value of its sister $\mathrm{X}$.

${ }^{10}$ We assume an N'-internal PRO movement within NP that leaves a trace $\mathrm{t} 2$ of type e. Such an empty category is to be focus-marked to shape the default absolute reading (Heim 1999, Krifka 1998, Romero 2011).

11 This kind of analysis was inspired by Labeaux (1988) who explained the asymmetry between adjuncts and complements in (34) in terms of late merger. Accordingly, complements cannot undergo late merger because they must merge prior to movement as required under Projection 
Principle in which the selectional property of lexical items must be satisfied throughout derivation (Chomsky 1981). Adjuncts, on the other hand, do not need to satisfy subcategorization and hence they may merge countercyclically.

1. a. *Which argument [that Johni is a genius] did hei believe?

b. Which argument [that Johni made] did hei believe?

(Fox 1999: 164)

${ }^{12}$ Other contexts is the late merger of than-clauses in comparatives (Bhatt and Pancheva 2004).

${ }^{13}$ Labeaux (1988) explained the asymmetry between adjuncts and complements as exemplified in (12) by proposing that adjuncts, but not complements, can merge late. Accordingly, complements must merge prior to movement as required under Projection Principle in which the selectional property of lexical items must be satisfied throughout derivation (Chomsky 1981). Adjuncts, on the other hand, do not need to satisfy subcategorization property and hence they may merge countercyclically.

${ }^{14}$ In this way, the computational complexity (i.e., memory load) is reduced to the smallest structure possible for the system to process (Chomsky 2005).

\section{References}

Abe, Jun. 2018. Late Merge and Phases for Anti-C-Command Requirements. Syntax 21 (2): 91-111.

Abney, Steven. 1987. The English noun phrase in its sentential aspect: Massachusetts Institute of Technology dissertation.

Alexiadou, Artemis and Chris Wilder. 1998. Adjectival modification and multiple determiners. Possessors, predicates and movement in the DP. Amsterdam: Benjamins.

Chomsky, Noam. 1981. Lectures on Government and Binding. Dordrecht: Foris.

Chomsky, Noam. 1998. Minimalist Inquiries: The Framework. MIT Occasional Papers in Linguistics 15.

Chomsky, Noam. 1995. The Minimalist Program (Studies in Linguistics 28), MIT Press, Cambridge, Mass.

Chomsky, Noam. 2005. On Phases. Foundational issues in linguistic theory, eds. R. Freidin, C. Otero \& M. L. Zubizarreta, 133-166. Cambridge, MA: MIT Press.

Corver, Norbert. 1997. Much-Support as Last Resort. Linguistic Inquiry 21: 119-164.

Cresswell, Max. 1976. “The semantics of degree”. In Montague grammar, edited by Barbara Partee, pp 261-292. New York: Academic Press.

Elghamry Khaled. 2002. Definiteness and Number Ambiguity in the Superlative Construction in Arabic. Lingua 114 (7): 897-910.

Fox Danny. 1999. Reconstruction, Binding Theory, and the Interpretation of Chains. Linguistic Inquiry 30 (2): 157-196.

Fox, Danny. 2002. Economy and Semantic Interpretation. MIT Press, Cambridge, Mass. 
Fox, Danny and Nissenbaum Jon. 2000. Extraposition and scope: A case for overt QR', in Proceedings of WCCFL 18, edited by S. Bird, A. Carnie, J. Haugen, and P. Norquest, pp. 132-144. Cascadilla Press, Somerville, Mass.

Hallman, Peter 2016. Superlatives in Syrian Arabic. Natural Language and Linguistic Theory 34 (4): 1281-1328.

Heim, Irene. 1985. Notes on comparatives and related matters. Unpublished manuscript, University of Texas at Austin.

Heim, Irene 1999. Notes on Superlatives. Ms., Austin: University of Texas.

Heim, Irene. 2001. "Degree operators and scope". In Audiatur Vox Sapientiae: A Festschrift for Arnim von Stechow, edited by Fery, Caroline and Wolfgang Sternefeld, pp. 214-239, Akademie Verlag, Berlin,

Heim, Irena and Angelika Kratzer. 1998. Semantics in Generative Grammar. Malden, Mass., Oxford: Kluwer.

Krifka, Manfred. 1998. Additive particles under stress. In Proceedings of SALT VIII, edited by D.Strolovitsch and D. Lawson. pp 111-128. Cornell, NY: CLC Publications.

Larson, Richard. 2000. ACD in AP. Paper presented at WCCFL 19, February 4-6, UCLA.

Lebeaux, D. 1988. Language acquisition and the form of grammar. $\mathrm{PhD}$ diss., University of Massachusetts, Amherst.

Panagiotidis, Phoenvos and Theodoros Marinis. 2011. Determiner spreading as DP-predication. Studia Linguistica 65 (1): 268-298.

Ritter, Elizabeth. 1991. “Two functional categories in noun phrases”. In Perspectives on Phrase Structure: Heads and Licensing edited by Rothstein. S, pp. 7-62. Academic Press, California

Romero, Maribel. 2011. Modal superlatives and 3-place vs. 2-place -est. The Baltic yearbook of cognition, logic and communication 6, 1-39. Manhattan: New Prairie Press.

Romero, Maribel. 2013. Modal superlatives: a compositional analysis. Natural Language Semantics 21:2. 79-110.

Ross, John Robert. 1964. A partial grammar of English superlatives. Master's Thesis, University of Pennsylvania.

Rullmann, Hotze. 1995. Maximality in the semantics of wh-constructions. Doctoral Dissertation, University of Massachusetts at Amherst.

Santon, Juliet. 2016. Wholesale late merger in A-bar movement: Evidence from preposition stranding. Linguistic Inquiry 47 (1): 89-124.

Schwarz, Bernhard. 2005. "Modal superlatives". In Proceedings of SALT 15, edited by E. Georgala and J. Howell, 187-204. Ithaca: CLC Publications.

Schwarzschild Roger and Wilkinson Karina. 2002. Quantifiers in Comparatives: A Semantics of Degree based on Intervals. Natural Language Semantics 10 (1): 1-41 
Seuren, Pieter A. M. 1973. "The comparative”. In Generative Grammar in Europe, edited by F. Kiefer \& N. Ruwet, 528-564. Dordrecht: D. Reidel Publishing Company.

Sharvit Yael, Stateva Penka. 2002. Superlative Expressions, Context, and Focus. Linguistics and Philosophy 25 (2): 453-504.

Siloni, Tal. 1997. Noun phrases and nominalizations: the syntax of DPs. Dordrecht: Kluwer von Stechow, Arnim. 1984. Comparing Semantic Theories of Comparison. Journal of Semantics 3 (1): 177.

Szabolcsi, Anna.1986. "Comparative superlatives”. In Papers in Theoretical Linguistics, edited by Naoki Fukui, Tova Rapoport \& Elizabeth Sagey, pp. 245-266. Cambridge, MA: MITWPL.

Takahashi, Shoichi and Sarah Hulsey. 2009. Wholesale Late Merger: Beyond the A/A' Distinction. Linguistic Inquiry 40 (1): 487-526. 